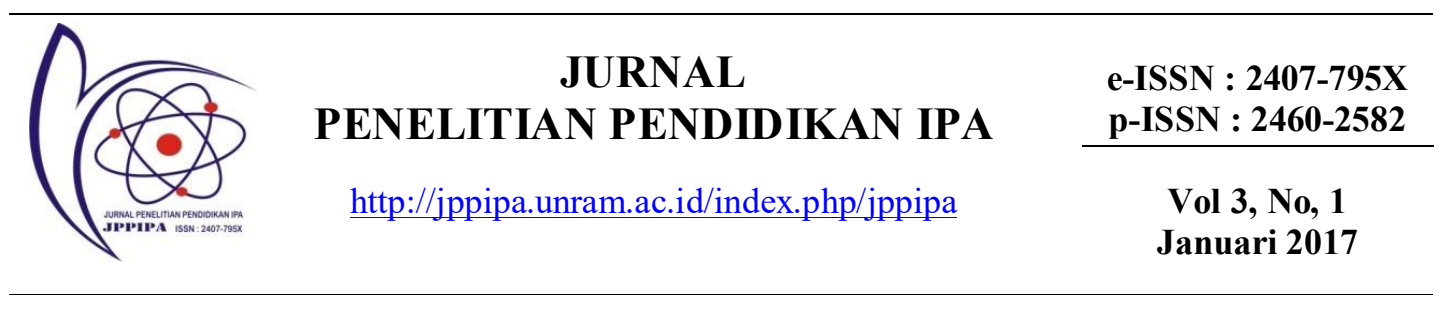

\title{
IDENTIFIKASI SENYAWA METABOLIT SEKUNDER PADA HASIL FRAKSINASI EKSTRAK Phaseolus vulgaris L. DENGAN METODE GAS CHROMATOGRAPHY-MASS SPECTROSCOPY (GC-MS)
}

\author{
Khurriyatul Khair ${ }^{1}$, Yayuk Andayani², Aliefman Hakim ${ }^{3}$ \\ Program Studi Magister Pendidikan IPA, Program Pascasarjana Universitas Mataram ${ }^{123}$ \\ Email:khurri@unram.ac.id
}

\begin{tabular}{|c|c|}
\hline Key Words & Abstract \\
\hline $\begin{array}{l}\text { P.vulgaris } \\
\text { L extract, } \\
\text { fractionatio } \\
\text { n, VLC, } \\
\text { GC-MS }\end{array}$ & $\begin{array}{l}\text { This research was aimed to identify some classes of secondary metabolite } \\
\text { compound on the fractionation results of green bean extract ( } P \text {. vulgaris L.) } \\
\text { using Gas Chromatography-Mass Spectroscopy (GC-MS) method. Green bean } \\
\text { was extracted by methanol solvent. Fractionation of methanol extract used } \\
\text { Vacuum Liquid Chromatography (VLC) with some variation of eluents such as } \\
\text { n-hexane } 100 \% \text {; n-hexane: ethyl acetate }(9: 1 \text { to } 1: 9) \text {; and ethyl acetate } 100 \% \text {, } \\
\text { produced } 11 \text { major fractions. Based on Thin Layer Chromatography (TLC) } \\
\text { analysis using DCM: MeOH (9.5: } 0.5) \text { as mobile phases, these } 11 \text { major fractions } \\
\text { were classified based on their polarity such as non-polar, semi-polar and polar } \\
\text { fraction. The results of identification by GC-MS spectrometer showed the } \\
\text { presence of secondary metabolites such as monoterpenes in non-polar fraction; in } \\
\text { semi-polar fraction was found terpenoids and steroids; in polar fraction was } \\
\text { found monoterpenes, phenolic and steroid as the lowest percent area, that is less } \\
\text { than } 2 \% \text {. }\end{array}$ \\
\hline Kata Kunci & Abstrak \\
\hline $\begin{array}{l}\text { Ekstrak } \\
\text { P.vulgaris } \mathrm{L} \text {, } \\
\text { fraksinasi, } \\
\mathrm{KCV}, G C- \\
M S\end{array}$ & $\begin{array}{l}\text { Penelitian ini bertujuan untuk mengidentifikasi golongan senyawa metabolit } \\
\text { sekunder pada hasil fraksinasi ekstrak buah buncis (P. vulgaris L.) dengan } \\
\text { metode Gas Chromatography-Mass Spectroscopy }(G C-M S) \text {. Buah buncis } \\
\text { diekstraksi dengan pelarut metanol. Fraksinasi ekstrak metanol dengan } \\
\text { kromatografi cair vakum (KCV) dengan variasi eluen } n \text {-heksan } 100 \% \text {; } n \text {-heksan } \\
\text { : etil asetat }=9: 1 \text { sampai } 1: 9 \text {; dan etil asetat } 100 \% \text {, menghasilkan } 11 \text { fraksi } \\
\text { utama. Berdasarkan uji kromatografi lapis tipis (KLT) dengan eluen } \\
\text { DCM:MeOH }(9,5: 0,5), 11 \text { fraksi utama hasil KCV digolongkan berdasarkan } \\
\text { kepolarannya yaitu fraksi nonpolar, semipolar dan polar. Hasil identifikasi } \\
\text { dengan spektrometer } G C-M S \text { menujukkan adanya senyawa metabolit sekunder } \\
\text { golongan monoterpen pada fraksi nonpolar; pada fraksi semipolar ditemukan } \\
\text { terpenoid dan steroid; dan pada fraksi polar ditemukan monoterpen, fenolik dan } \\
\text { steroid dengan } \% \text { area terandah yaitu kurang dari } 2 \% \text {. }\end{array}$ \\
\hline
\end{tabular}




\section{PENDAHULUAN}

Buncis merupakan salah satu tanaman yang berkhasiat meluruhkan kencing (diuretik) dan menurunkan kadar glukosa darah (sebagai antihiperglikemik), diduga karena peran senyawa aktif $\beta$-sitosterol dan stigmasterol (Andayani, 2003). Karena khasiatnya tersebut, maka ekstrak buah buncis telah diproduksi dalam bentuk sediaan serbuk yang dikemas dalam bentuk kapsul. Kemampuan aktivitas antioksidan dari ekstrak Phaseolus vulgaris L. telah dilaporkan oleh Kurnia (2013), sedangkan Nugrahani (2015) melaporkan bahwa serbuk ekstrak buah buncis memiliki aktivitas antioksidan, diduga karena mengandung senyawa golongan flavonoid. Penelitian yang dilakukan Lam (2010) menyebutkan bahwa biji buncis dapat bertindak sebagai antitumor, antijamur dan antiHIV-1 reverse transcriptase.

Buncis (P. vulgaris L.) dikonsumsi secara luas oleh masyarakat sebagai sayuran. Penelitian mengenai kandungan fitokimia dari tanaman buncis ini telah dilakukan, diantaranya Jannah (2013) melaporkan hasil uji Kromatografi Lapis Tipis menunjukkan adanya kandungan senyawa fitosterol dalam ekstrak buah buncis, Balafif
(2013) menemukan adanya kandungan senyawa golongan triterpenoid dalam fraksi partisi metanol dari ekstrak air buah buncis dan Risnafiani (2015) melaporkan kandungan fitokimia dari daun buncis diantaranya adalah senyawa golongan steroid, alkaloid, kuinon, tannin, flavonoid, polifenol, monoterpen dan seskuiterpen. Atchibri, et al. (2010) melaporkan aktivitas antidiabetes dan kandungan fitokimia dari biji $P$. vulgaris L. yang terdiri atas alkaloid, antrakuinon, catechic tannins, flavonoid, gallic tannins, glikosida, polifenol, saponin, steroid dan terpenoid. Walaupun telah banyak dilakukan penelitian mengenai profil fitokimia dari tanaman ini, identifikasi golongan senyawa metabolit sekunder pada hasil fraksinasi kromatografi cair vakum (KCV) dari buah buncis dengan spektrometer GC-MS belum pernah dilaporkan. Berdasarkan uraian di atas maka dipandang perlu mengidentifikasi dan membandingkan senyawa-senyawa metabolit sekunder yang terdapat pada hasil fraksinasi ekstrak metanol buah buncis.

Penelitian ini diharapkan dapat digunakan sebagai sumber informasi ilmiah mengenai senyawa-senyawa metabolit sekunder dari buah buncis 
yang tergolong dalam fraksi polar, semipolar dan nonpolar yang berguna untuk pengembangan ilmu kimia bahan alam dan memberikan peluang untuk dilakukannya penelitian lanjutan untuk mengetahui bioaktivitas dari senyawa metabolit sekunder dari buncis ini.

\section{METODE PENELITIAN}

Metode yang digunakan dalam penelitian ini adalah metode penelitian deskriptif-eksploratif untuk menganalisis senyawa metabolit sekunder hasil fraksinasi ekstrak buah buncis yang dilakukan melalui tahapan ekstraksi, fraksinasi dengan metode kromatografi cair vakum (KCV), analisis hasil fraksinasi dilakukan dengan metode kromatografi lapis tipis (KLT) yang dilaksanakan di laboratorium Kimia Dasar FMIPA Universitas Mataram dan analisis dengan metode spektroskopi GC-MS dilaksanakan di LAboratorium Kimia Universitas Udayana. Bahan yang digunakan dalam penelitian ini adalah 1 kg serbuk kering buah buncis, metanol teknis, metanol pro-analysis, n-heksan teknis, diklorometana (DCM) proanalysis, etil asetat teknis, plat KLT silika gel $60 \mathrm{~F}_{254}$ berlapis alumunium, silika gel $60 \quad \mathrm{G}$ dan silika gel impreknasi. Alat yang digunakan dalam penelitian ini lampu UV $\lambda_{254}$ dan $\lambda_{366}$, corong pisah, erlenmeyer, gelas kimia, gelas ukur, pipa kapiler, pipet tetes, spatula, bejana pengembang (chamber), neraca analitik, dan botol kaca $150 \mathrm{~mL}$, peralatan destilasi (rotary evaporator) dan peralatan kromatografi cair vakum (KCV). Pada tahap identifikasi senyawa metabolit sekunder digunakan spektrometer $G C-M S$.

\section{Ekstraksi Buah Buncis (Phaseolus vulgaris L.)}

Ekstraksi buah buncis dilakukan dengan cara maserasi bertingkat yaitu perendaman buah buncis kering sebanyak 1000 gram pelarut metanol sebanyak $3000 \mathrm{ml}$ selama 1 x 24 jam dengan sekali-kali pengocokan. Kemudian maserat (maserat A) dipisahkan dari ampas setelah 24 jam maserasi dan ditampung dalam bejana lain. Remaserasi dilakukan dengan memasukan pelarut sebanyak $2000 \mathrm{ml}$ ke dalam bejana yang berisi residu (ampas),dan dilakukan pengocokan, lalu dibiarkan 24 jam. Maserat B dipisahkan setelah 24 jam, kemudian mencampur maserat A dan B. Remaserasi dilakukan kembali selama 1 x 24 jam hingga diperoleh maserat $\mathrm{C}$ dengan $1000 \mathrm{~mL}$ metanol. Maserat A, B, C dicampur dan dilakukan evaporasi dengan 
menggunakan alat rotary evaporator hingga diperoleh ekstrak metanol pekat.

Fraksinasi Ekstrak Metanol Buah Buncis (Phaseolus vulgaris L.) dengan Metode Kromatografi Cair Vakum (KCV)

Ekstrak hasil evaporasi (ekstrak metanol buah buncis) difraksinasi dengan $\mathrm{KCV}$ (eluen $n$-heksan $100 \%$; $n$-heksan : etil asetat $=9: 1$ sampai $1: 9$; dan etil asetat $100 \%$ ) dengan fase diam silika gel 60 G. Fraksi-fraksi yang keluar dari kolom ditampung ke dalam botol kaca $150 \mathrm{~mL}$ dan dimonitoring dengan kromatorafi lapis tipis (KLT). Fraksi-fraksi yang memiliki spot dengan $\mathrm{Rf}$ yang sama atau mirip pada plat KLT dijadikan satu fraksi besar/utama dan digolongkan berdasarkan kepolarannya.

Identifikasi Kepolaran Fraksi-Fraksi Hasil KCV Ekstrak Metanol P. vulgaris L. dengan Metode KLT

Kromatografi Lapis Tipis (KLT) dilakukan terhadap ekstrak dan hasil fraksinasi ekstrak metanol buah buncis. Langkah analisis KLT adalah sebagai berikut: chamber kromatografi diisi dengan eluen DCM : $\mathrm{MeOH}(9,5: 0,5)$, ditotolkan ekstrak dan fraksi-fraksi hasil kromatografi cair vakum (KCV) pada bagian plat KLT yang telah diberi tanda sebelumnya, dimasukkan plat KLT ke dalam chamber yang berisi eluen, dan diangkat plat KLT jika eluen telah mencapai batas yang telah ditentukan. Spot-spot yang muncul pada plat KLT diamati dengan menggunakan lampu UV 254 dan 366.

Identifikasi Senyawa Metabolit Sekunder Fraksi Nonpolar, Semipolar dan Nonpolar Ekstrak Metanol P. vulgaris $\mathrm{L}$. dengan spektrometer GCMS

Identifikasi kandungan senyawa metabolit sekunder dilakukan dengan menggunakan Spektrometer GC-MS. Fraksi nonpolar, semipolar dan polar masing-masing diinjeksikan ke dalam alat $G C-M S$. Kondisi running GC-MS QP-2010 Ultra dilakukan pada temperatur oven kolom sebesar $70^{\circ} \mathrm{C}$ $270^{\circ} \mathrm{C}$, sedangkan temperatur injeksi $250^{\circ} \mathrm{C}$. Gas pembawa yang digunakan adalah gas helium dengan tekanan sebesar 76,1 $\mathrm{kPa}$ dan laju alir 1,19 $\mathrm{mL} / \mathrm{menit}$.

\section{HASIL DAN PEMBAHASAN}

Ekstraksi dilakukan dengan cara maserasi menghasilkan maserat sebanyak 5,25 L diuapkan dengan alat rotary evaporator pada suhu $42^{\circ} \mathrm{C}$ $45^{\circ} \mathrm{C}$ menghasilkan $100 \mathrm{~mL}$ ekstrak kental buah buncis dan terbentuk 3 lapisan dimana lapisan ketiga memiliki hasil terbaik berdasarkan uji KLT. Fraksinasi 10 gram lapisan ketiga 
ekstrak metanol buah buncis berdasarkan uji KLT pada tiap fraksi menghasilkan 11 fraksi utama dimana fraksi dengan spot yang mirip dengan eluen DCM:MeOH (9,5:0,5). Gambar 1 menunjukkan hasil uji KLT disatukan. Hasil fraksinasi dengan $\mathrm{KCV}$ dikelompokkan menjadi kelompok fraksi nonpolar, semipolar dan polar fraksi-fraksi hasil KCV dan Tabel 1 merupakan penggolongan fraksi-fraksi berdasarkan kepolarannya.

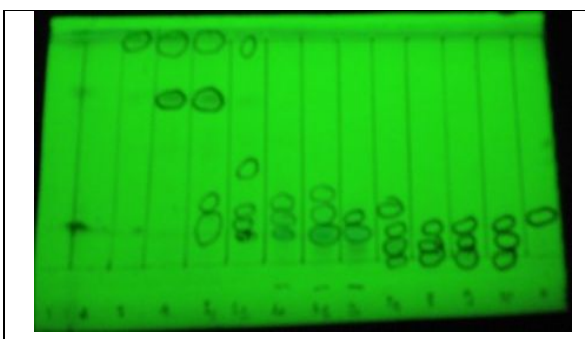

(a) sinar UV $\lambda_{254}$

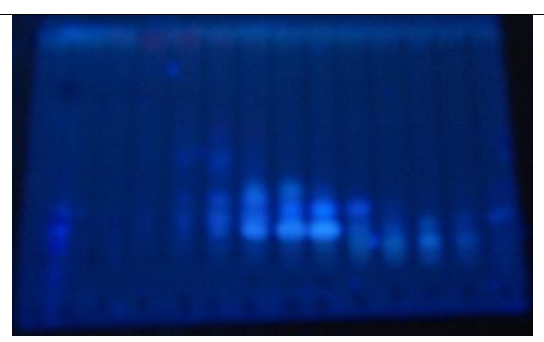

(b) sinar UV $\lambda_{366}$

Gambar 1. Kromatogram KLT fraksi-fraksi KCV dengan eluen DCM: $\mathrm{MeOH}(9,5: 0,5)$

Tabel 1. Tabel penggolongan kepolaran hasil fraksinasi KCV ekstrak metanol buah buncis.

\begin{tabular}{|c|c|c|c|c|c|c|c|}
\hline \multirow[t]{2}{*}{ Fraksi } & \multirow[t]{2}{*}{ Eluen } & \multicolumn{5}{|c|}{ Nilai Rf Spot ke - } & \multirow[t]{2}{*}{ Pengelompokan } \\
\hline & & 1 & 2 & 3 & 4 & 5 & \\
\hline 1 & n-heksan $100 \%$ & - & - & - & - & - & Nonpolar \\
\hline 2 & n-heksan : EtOAc 9:1 & - & - & - & - & - & Nonpolar \\
\hline 3 & n-heksan : EtOAc 8:2 & 1 & - & - & - & - & Nonpolar \\
\hline 4 & n-heksan : EtOAc 7:3 & 1 & 0,72 & - & - & - & Nonpolar \\
\hline $5 \mathrm{~A}$ & n-heksan : EtOAc 6:4 & 1 & 0,72 & 0,27 & 0,15 & - & Semipolar \\
\hline $5 \mathrm{~B}$ & n-heksan : EtOAc 6:4 & 0,96 & 0,38 & 0,22 & 0,17 & 0,12 & Semipolar \\
\hline $6 \mathrm{~A}$ & n-heksan : EtOAc $1: 1$ & 0,26 & 0,19 & 0,12 & - & - & Semipolar \\
\hline $6 \mathrm{~B}$ & n-heksan : EtOAc 1:1 & 0,27 & 0,19 & 0,12 & - & - & Semipolar \\
\hline $7 \mathrm{~A}$ & n-heksan : EtOAc 4:6 & 0,17 & 0,12 & - & - & - & Semipolar \\
\hline $7 \mathrm{~B}$ & n-heksan : EtOAc 4:6 & 0,20 & 0,12 & 0,05 & - & - & Semipolar \\
\hline 8 & n-heksan : EtOAc 3:7 & 0,12 & 0,05 & - & - & - & Polar \\
\hline 9 & n-heksan : EtOAc $2: 8$ & 0,13 & 0,07 & - & - & - & Polar \\
\hline 10 & n-heksan : EtOAc 1:9 & 0,13 & 0,07 & - & - & - & Polar \\
\hline 11 & EtOAc $100 \%$ & 0,07 & - & - & - & - & Polar \\
\hline
\end{tabular}

Penggolongan fraksi-fraksi hasil $\mathrm{KCV}$ didasarkan pada kepolarannya, mulai dari nonpolar, semipolar dan polar. Kromatogram hasil fraksinasi
$\mathrm{KCV}$ yaitu fraksi 1 sampai dengan 11 menghasilkan noda dengan berbagai variasi Rf dan terdapat juga spot yang mirip. Hasil KLT menunjukkan belum 
adanya senyawa yang terfraksinasi pada fraksi 1 dan 2, sedangkan pada fraksi 3 dan 4, tampak spot/noda dengan nilai $\mathrm{Rf}$ yang besar atau spot-spot yang dihasilkan terelusi jauh mendekati jarak tempuh eluen. Kepolaran suatu senyawa dari hasil uji KLT ditentukan oleh sejauh mana senyawa terelusi oleh eluen yang digunakan. Semakin jauh terelusi maka semakin nonpolar sifat dari fraksi tersebut, atau semakin besar nilai $\mathrm{Rf}$ maka semakin nonpolar sifat dari suatu senyawa. Hal ini dapat dipahami karena pada fasa diam, plat KLT bersifat polar, sedangkan eluen KLT yang digunakan harus memiliki kepolaran yang lebih rendah daripada plat KLT, sehingga hanya senyawasenyawa dengan sifat polar yang dapat tertinggal pada fasa diam (plat KLT), sedangkan senyawa-senyawa nonpolar akan terelusi jauh oleh fasa gerak (eluen) meninggalkan fasa diam. Dengan demikian, berdasarkan kromatogram KLT hasil fraksinasi $\mathrm{KCV}$ ekstrak metanol buah buncis, fraksi 1-4 digolongkan ke dalam fraksi nonpolar, fraksi 5-7 merupakan fraksi semipolar dan fraksi 8-11 merupakan fraksi polar.

Fraksi 1-4 memiliki perbandingan eluen $\mathrm{KCV}$ dengan jumlah n-heksan lebih banyak dibandingkan dengan jumlah etil asetat sehingga akan melarutkan senyawasenyawa nonpolar pada fraksinasi dengan $\mathrm{KCV}$, sedangkan fraksi 5-7 memiliki perbandingan eluen dengan jumlah n-heksan dan etil asetat yang hampir sama sehingga dapat melarutkan senyawa-senyawa yang bersifat semipolar. Fraksi 8-11 memiliki perbandingan eluen $\mathrm{KCV}$ dengan jumlah etil asetat lebih banyak dibandingkan dengan jumlah n-heksan, sehingga dapat melarutkan senyawasenyawa polar. Dengan demikian pada analisis KLT senyawa-senyawa yang teridentifikasi pada fraksi 1-4 digolongkan dalam kelompok senyawa yang bersifat nonpolar, fraksi 5-7 bersifat semipolar dan fraksi 8-11 bersifat polar.

Hasil identifikasi senyawasenyawa metabolit sekunder pada fraksi nonpolar, semipolar dan polar dari hasil fraksinasi ekstrak metanol buah buncis dengan spektrometer $G C-M S$ yang running pada temperatur oven kolom $70^{\circ} \mathrm{C}-270^{\circ} \mathrm{C}$, temperatur injeksi $250^{\circ} \mathrm{C}$ dengan gas pembawa helium pada tekanan $76,1 \mathrm{kPa}$ dan laju alir 1,19 $\mathrm{mL} /$ menit, dapat dilihat pada Tabel 2. Identifikasi dengan $G C$ - $M S$ menujukkan adanya senyawa metabolit sekunder 
golongan monoterpen pada fraksi nonpolar; golongan terpenoid dan steroid pada fraksi semipolar; golongan monoterpen, fenol dan steroid pada fraksi polar dengan $\%$ area terandah yaitu kurang dari 2\%. Hal ini dapat dipahami karena umumnya senyawa metabolit sekunder golongan steroid dan flavonoid bersifat semipolar dan nonpolar bergantung pada gugus fungsi yang diikat oleh kerangka utamanya, dengan demikian pada fraksi polar \% area dari senyawa-senyawa metabolit sekunder memiliki nilai yang paling rendah dibandingkan dengan nilai $\%$ area fraksi yang lainnya.

Tabel 2. Hasil Analisis GC-MS Senyawa Metabolit Sekunder pada Tingkat Fraksi

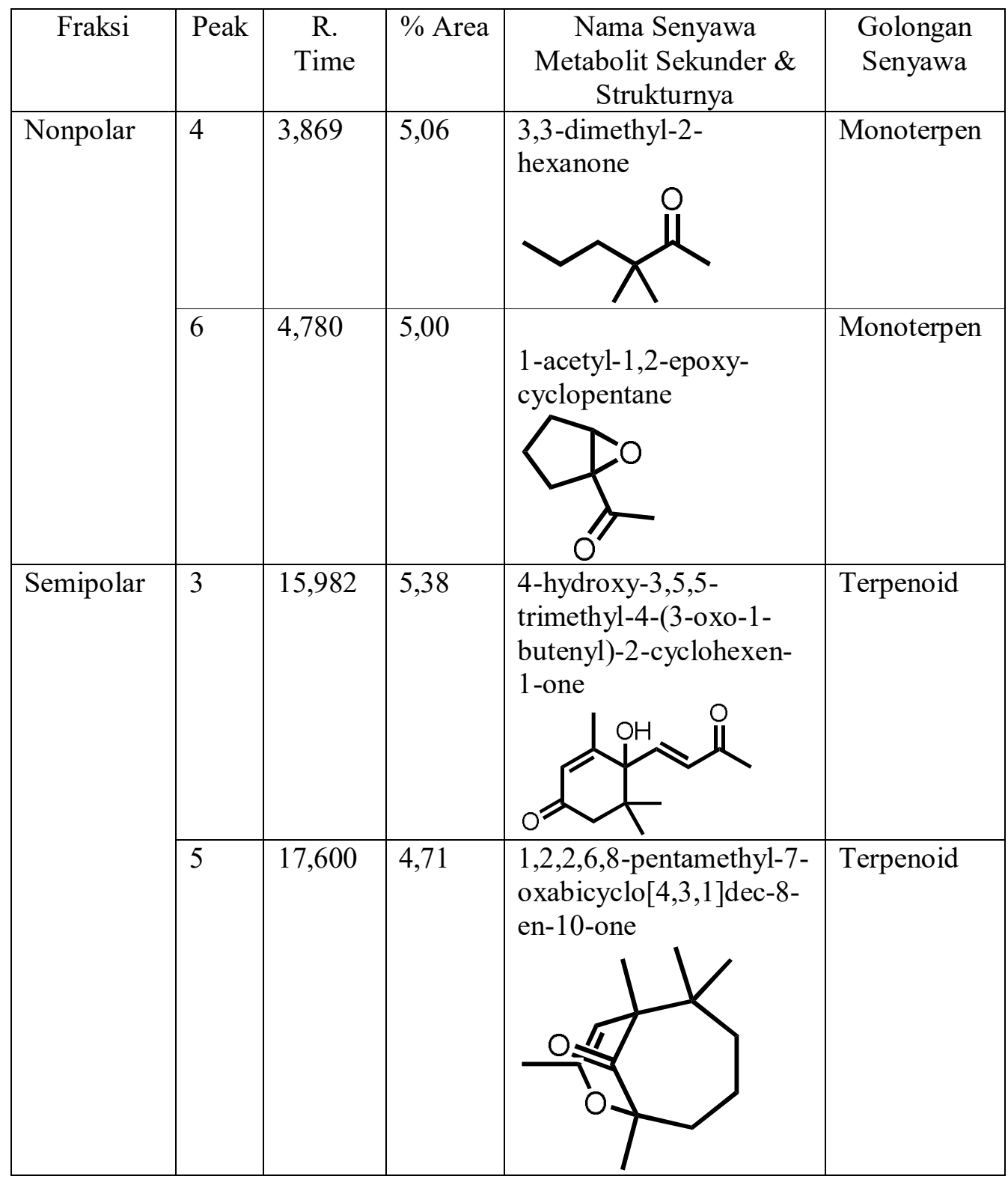




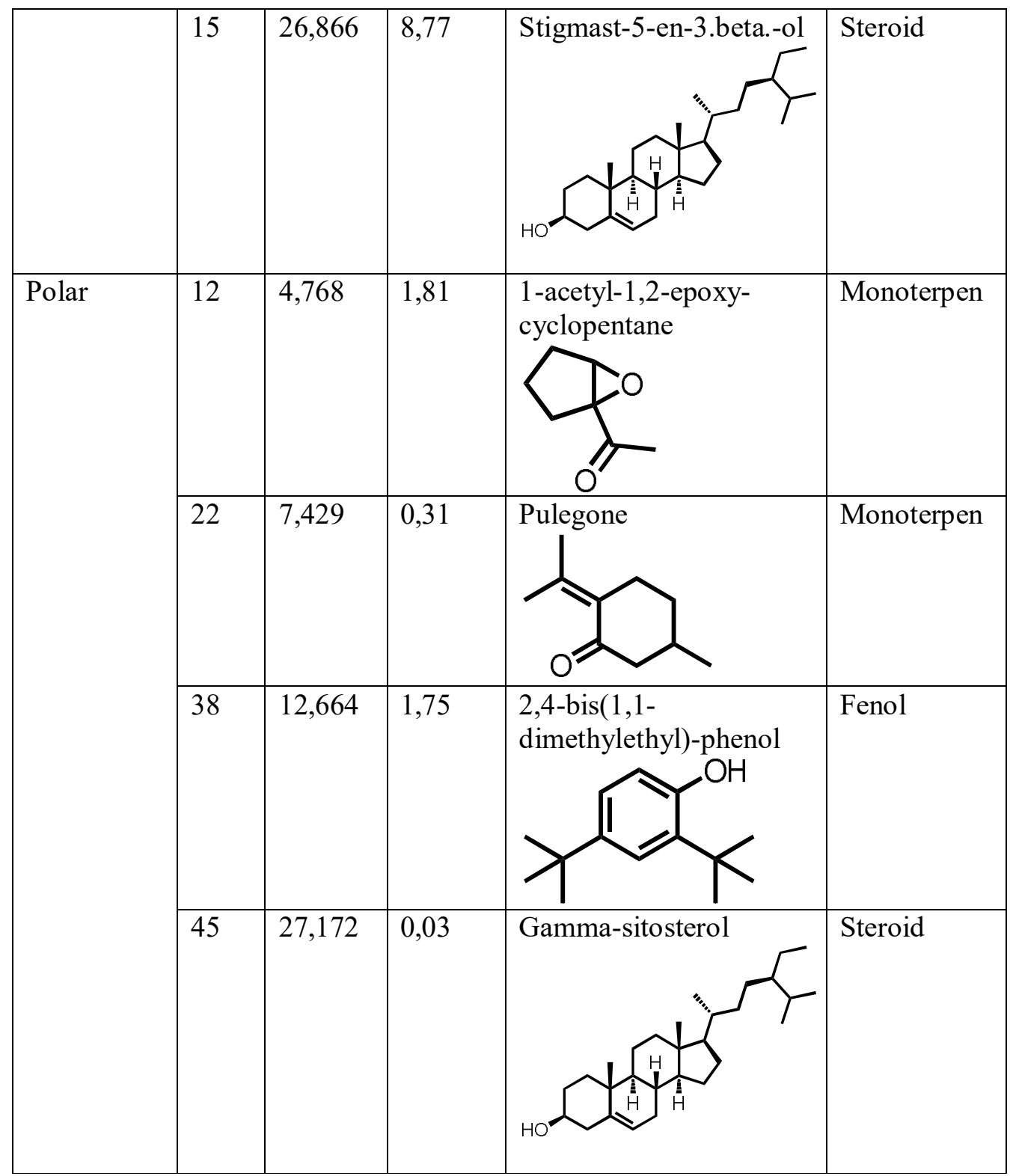

Hasil analisis $G C$-MS pada fraksi nonpolar menunjukkan terdapat dua senyawa yang tergolong dalam monoterpen yaitu 3,3-dimethyl-2hexanone dengan $\%$ area $5,06 \%$ dan 1acetyl-1,2-epoxy-cyclopentane dengan \% area 5,00\%. Monoterpen merupakan senyawa yang disusun oleh dua unit isoprena dengan jumlah atom $\mathrm{C}$ sebanyak 10. Penelitian yang dilakukan oleh Balafif, dkk (2013) menemukan adanya kandungan triterpenoid pada ekstrak metanol hasil partisi ekstrak air buah buncis dengan \% area 4,66\%. Triterpenoid terdiri atas 6 unit isoprena dengan jumlah atom $\mathrm{C}$ sebanyak 30. 
Hasil analisis dengan $G C$-MS pada fraksi semipolar menunjukkan terdapat dua senyawa golongan terpenoid yaitu 4hydroxy-3,5,5-trimethyl-4-(3-oxo-1butenyl)-2-cyclohexen-1-one dengan \% area 5,38\% dan 1,2,2,6,8-pentamethyl-7oxabicyclo[4,3,1]dec-8-en-10-one dengan $\%$ area $4,71 \%$. Metabolit sekunder lain yang teridentifikasi adalah golongan steroid yaitu stigmast-5-en-3.beta.-ol dengan $\%$ area 8,77 . Penelitian yang dilakukan oleh Jannah, dkk (2013) menemukan kandungan senyawa stigmasterol dengan $\%$ area $2,48 \%$ pada ekstrak kasar yaitu ekstrak etanol buah buncis. Hal ini menunjukkan bahwa jumlah stigmasterol yang teridentifikasi pada fraksi semipolar ekstra metanol lebih banyak dibandingkan dengan ekstrak etanol buah buncis. Metanol sebagai pelarut memiliki ukuran molekul yang lebih kecil dibandingkan dengan etanol sehingga dapat mengkstrak senyawa metabolit sekunder lebih banyak.

Hasil analisis $G C-M S$ pada fraksi polar menunjukkan terdapat dua senyawa golongan monoterpen yaitu 1-acetyl-1,2epoxy-cyclopentane dengan $\%$ area $1,81 \%$ dan pulegon dengan $\%$ area $0,31 \%$.

\section{DAFTAR PUSTAKA}

Andayani, Y. 2003. Mekanisme Aktivitas Antihiperglikemik Ekstrak Buncis (Pheseolus
Metabolit sekunder golongan fenol yang teridentifikasi adalah 2,4-bis(1,1dimethylethyl)-phenol dengan $\%$ area $1,75 \%$. Golongan steroid yang teridentifikasi pada fraksi ini adalah gamma-sitosterol dengan $\%$ area $0,03 \%$. Senyawa metabolit sekunder golongan fenol hanya ditemukan pada fraksi polar, walaupun dengan persentase area yang rendah yaitu $1,75 \%$. Hal ini menunjukkan bahwa fenolik yang terkandung dalam buah buncis bersifat polar.

Tidak teridentifikasinya senyawa metabolit sekunder yang lain pada fraksifraksi hasil fraksinasi ekstrak metanol buah buncis diduga karena keterbatasan senyawa-senyawa standar yang terdapat pada library spektrometer GC-MS.

\section{KESIMPULAN}

Hasil identifikasi dengan Gas Chromatography Mass Spectrometer (GC$M S)$ menujukkan adanya senyawa metabolit sekunder golongan monoterpen; golongan terpenoid dan steroid pada fraksi semipolar; golongan monoterpen, fenol dan steroid pada fraksi polar dengan $\%$ area terandah yaitu kurang dari $2 \%$.

vulgaris L.) pada Tikus Diabetes dan Identifikasi Komponen Aktif. Disertasi S3. Institut Pertanian Bogor. 
Atchibri, A.L. Ocho Anin., Brou., Kouakou., Kouadlo dan Gnakri. 2010. Screening for Antidiabetic Activity and Phytochemical Constituents of Common Bean (Phaseolus vulgaris L.) Seeds. Journal of Medicinal Plant Research, Vol. 4(17), pp. 1757-1761.

Balafif, R.A.R., Andayani, Y., dan Gunawan, E.R. 2013. Analisis Senyawa Triterpenoid dari Hasil Fraksinasi Ekstrak Air Buncis (Pheseolus vulgaris L.). Chemical Program Vol. 6 No.2, hal 56-61.

Jannah, H., Sudarma I M., dan Andayani, Y. 2013. Analisis Senyawa Fitosterol dalam Ekstrak Buah Buncis (Pheseolus vulgaris L.). Chemical Program Vol. 6 No. 2, hal 71-75.

Kurnia, N. 2013. Uji Aktivitas Antioksidan Ekstrak Air Buah
Buncis (Pheseolus vulgaria L.). Tasis S2. Universitas Mataram.

Lam, S.K. 2010. Isolation and Characterization of a French Bean Hemagglutinin with Antitumor, Antifungal and Anti-HIV-1 Reverse Transcriptase Activities and an Exceptionally High Yield. Phytomedicine, 17, 457-462.

Nugrahani, R. 2015. Analisis Potensi Serbuk Ekstrak Buncis Pheseolus vulgaris L.). Tesis S2. Universitas Mataram.

Risnafiani, A.R., Rismawati, E. dan Hilda A. 2015. Karakterisasi Daun Buncis (Phaseolus vulgaris L.) dan Identifikasi Kandungan Senyawa Steroid dengan Metode Kromatografi Lapis Tipis dan Kromatografi Cair Kinerja Tinggi. Prosiding Penelitian SPeSIA Unisba 2015. 